\title{
Cloning, sequencing, and mutational analysis of the Bradyrhizobium japonicum fum $C$-like gene: evidence for the existence of two different fumarases
}

\author{
Gonzalo Acuña, Sabine Ebeling and Hauke Hennecke* \\ Mikrobiologisches Institut, Eidgenössiche Technische Hochschule, Schmelzbergstrasse 7, CH-8092 Zürich, Switzerland
}

(Received 13 September 1990; revised 28 November 1990; accepted 11 December 1990)

\begin{abstract}
The Bradyrhizobium japonicum fumarase gene ( $f u m C$-like) was cloned and sequenced, and a fum $C$ deletion mutant was constructed. This mutant had a $\mathrm{Nod}^{+} \mathrm{Fix}^{+}$phenotype in symbiosis with the host plant, soybean, and growth in minimal medium with fumarate as sole carbon source was also not affected. The cloned $B$. japonicum fumC gene fully complemented an Escherichia coli $\mathrm{Fum}^{-}$mutant, strain $\mathrm{JH400}$, for growth in minimal medium with fumarate. The predicted amino acid sequence of the FumC protein showed strong similarity to the $E$. coli FumC protein, Bacillus subtilis CitG protein, Saccharomyces cerevisiae Fum1 protein, and the mammalian fumarases. The $B$. japonicum FumC protein accounted for about $40 \%$ of the total fumarase activity in aerobically grown cells. The remaining $60 \%$ was ascribed to a temperature-labile fumarase. These data suggest that $B$. japonicum possesses two different fumarase isoenzymes, one of which is encoded by $f u m C$. Besides $E$. coli, which has three fumarases, $B$. japonicum is thus the second bacterium for which there is genetic evidence for the existence of more than one fumarase.
\end{abstract}

\section{Introduction}

Biological nitrogen fixation demands a substantial amount of energy and reductant. In the nitrogen-fixing Rhizobium-legume symbiosis this requirement is met exclusively by the photosynthate supply from the host plant. The elucidation of the central rhizobial pathways by which the endosymbiotic bacteroids metabolize the plant-derived carbon sources is a subject of considerable interest in order to understand the physiology of root nodule symbiosis.

There are several lines of evidence that a functional citric acid cycle plays an essential role in bacteroid carbon metabolism. For example, Rhizobium meliloti mutants defective in 2-oxoglutarate dehydrogenase (Duncan \& Fraenkel, 1979) or in succinate dehydrogenase (Gardiol et al., 1982) induced nitrogen non-fixing $\left(\mathrm{Fix}^{-}\right)$nodules on alfalfa. The results from studies on the uptake of radiolabelled carbon substrates performed with isolated bacteroids were consistent with the existence of a functional tricarboxylic acid (TCA) cycle

Abbreviations: ORF, open reading frame; TCA, tricarboxylic acid.

The nucleotide sequence data reported in this paper have been submitted to GenBank and have been assigned the accession number M38241.
(Stovail \& Cole, 1978). Moreover, the specific activities of several TCA cycle enzymes in different rhizobial bacteroids were shown to increase in parallel with the increase of nitrogenase activity (Robertson \& Taylor, 1973; Kurz \& LaRue, 1977; Karr et al., 1984; McKay et al., 1989). Finally, the $\mathrm{C}_{4}$-dicarboxylates were recognized as the most effective substrates for respiration and for promoting nitrogen fixation (Bergersen \& Turner, 1967), which indirectly supported the assumption that the TCA cycle played a major role in bacteroid metabolism. This was confirmed genetically by the observation that $\mathrm{C}_{4}$ dicarboxylate transport (dct) mutants of Bradyrhizobium japonicum (Humbeck \& Werner, 1988), R. meliloti (Bolton et al., 1986; Engelke et al., 1989), Rhizobium leguminosarum biovar viciae (Finan et al., 1983), and $R$. leguminosarum biovar trifolii (Ronson et al., 1981) formed ineffective nodules on their host plants.

Fumarase (fumarate hydratase; EC 4.2.1 .2) catalyses the interconversion of fumarate and L-malate and functions as an integral step of the TCA cycle in aerobic metabolism and, in some organisms, in the reductive branch of the cycle during fermentation and anaerobic fumarate respiration. Recent work has revealed the existence of two classes of fumarases (Woods et al., $1988 b$; Yumoto \& Tokushige, 1988). Class I fumarases 
Table 1. Bacterial strains and plasmids

\begin{tabular}{|c|c|c|}
\hline $\begin{array}{l}\text { Strain or } \\
\text { plasmid }\end{array}$ & Relevant genotype or phenotype & Reference or origin \\
\hline \multicolumn{3}{|l|}{ E. coli } \\
\hline HB101 & $h s d R$ hsd $M$ recAl3 strA & Boyer \& Roulland-Dussoix (1969) \\
\hline $\mathrm{JH} 400$ & $\Delta(d g s-$ fum $C A-$ man $A) \mathrm{D} 1 \Delta($ mel-fumB $) z d g-232:: \mathrm{Tn} 10$ met $B I$ spoTI relA & Henson et al. (1987) \\
\hline JM101 & $\Delta($ lac-proAB $) \mathrm{F}^{\prime}\left(\right.$ traD 36 proAB $\left.B^{+} l a c I^{q_{-}} \Delta M 15\right)$ & Messing (1983) \\
\hline JM109 & hsdRI7 recAl & Messing (1983) \\
\hline S17-1 & hsdR RP4-2kan: :Tn7 tet : : Mu (chromosomally located) & Simon et al. (1983) \\
\hline \multicolumn{3}{|l|}{ B. japonicum } \\
\hline $110 \operatorname{spc} 4$ & $\mathrm{Spc}^{\mathrm{R}}$ (referred to as wild-type) & Regensburger \& Hennecke (1983) \\
\hline 110 rif 15 & Rif ${ }^{R}$ & Regensburger \& Hennecke (1984) \\
\hline 259 & $\mathrm{Fix}^{-} \mathrm{Tn} 5$ mutant of 110 rifls: $\mathrm{Km}^{\mathrm{R}} \mathrm{Rif}^{\mathrm{R}}$ & Regensburger et al. (1986) \\
\hline $\mathrm{FC}^{*}$ & fum $C$ deletion mutant $(1.2 \mathrm{~kb} S p h \mathrm{I}$ fragment $)$ of the wild-type; $\mathrm{Km}^{\mathrm{R}} \mathrm{Spc}^{\mathrm{R}}$ & This work \\
\hline \multicolumn{3}{|c|}{ Vectors and recombinant plasmids } \\
\hline $\begin{array}{l}\text { M13mpl8 } \\
\text { M13mpl9 }\end{array}$ & Sequencing vectors & Norrander et al. (1983) \\
\hline $\mathrm{pBLS}(\mathrm{KS})+$ & $A p^{R}$ & Stratagene, La Jolla, CA, USA \\
\hline pGS210 & E. coli fumC in $\mathrm{pUCl} 12$ & Woods \& Guest (1987) \\
\hline pJF118EH & lac $\mathrm{I}^{\mathrm{q}}+$ derivative of the expression vector $\mathrm{pKK} 223-3 ; \mathrm{Ap}^{\mathrm{R}}$ & Fürste et al. (1986) \\
\hline pRK 290pol2 & pRK290 $\mathrm{Tc}^{\mathrm{R}} \mathrm{Mob}^{+}$with the pBLS polylinker in the EcoRI site & P. Grob, ETH Zürich \\
\hline pRK 2013 & $\mathrm{Km}^{\mathrm{R}} \mathrm{Tra}^{+}$for bi-parental mating & Figurski \& Helinski (1979) \\
\hline pSUP202 & $A p^{R} \mathrm{Km}^{\mathrm{R}} \mathrm{Cm}^{\mathrm{R}} ;$ oriT from RP4 & Simon et al. (1983) \\
\hline pUC4-KIXX & $\mathrm{Ap}^{\mathrm{R}} \mathrm{Km}^{\mathrm{R}}$; source of the $\mathrm{Km}^{\mathrm{R}} 1.2 \mathrm{~kb}$ Smal fragment & Pharmacia, Uppsala Sweden \\
\hline pL20-11H & $\begin{array}{l}\text { Cosmid clone carrying the wild-type region corresponding to the } \operatorname{Tn} 5 \\
\text { mutation of mutant } 259\end{array}$ & Regensburger (1986) \\
\hline pRJ $2034 \dagger$ & $5 \cdot 5 \mathrm{~kb}$ BamHI-Bg/II subclone of pL20-11H in pUC19 & This work \\
\hline $\mathrm{pRJ} 2200+$ & $3.7 \mathrm{~kb}$ Pstl fragment of pRJ 2034 in the PstI site of pBLS (KS) + & This work \\
\hline pRJ2201† & $\begin{array}{l}1.2 \mathrm{~kb} S p h \mathrm{I} \text { deletion of pRJ } 2200 \text { replaced by } 1.2 \mathrm{~kb} \mathrm{Km}^{\mathrm{R}} \text { SmaI fragment } \\
\text { from pUC4-KIXX }\end{array}$ & This work \\
\hline $\mathrm{pRJ} 2202 †$ & $\begin{array}{l}3.7 \mathrm{~kb} E c o \mathrm{RI}-\text { Bam HI fragment of pRJ } 2201 \text { in the EcoRI/PstI sites of } \\
\text { pSUP202 }\end{array}$ & This work \\
\hline $\mathrm{pRJ} 2204 \dagger$ & $\begin{array}{l}2.7 \mathrm{~kb} X h o \mathrm{I} \text { fragment of } \mathrm{pRJ} 2200 \text { in the } S a / \mathrm{I} \text { site of } \mathrm{pJF} 118 \mathrm{EH} \text { with }{ }_{p} t a c \\
\text { opposite to fumC }\end{array}$ & This work \\
\hline $\mathrm{pRJ} 2205 \dagger$ & $\begin{array}{l}3.7 \mathrm{~kb} \mathrm{BamHI}-\text { HindIII fragment of } \mathrm{pRJ} 2200 \text { in the BamHI/HindIII sites of } \\
\text { pJF118EH with fumC under the control of }{ }_{p} \text { tac }\end{array}$ & This work \\
\hline pRJ2217† & $2.9 \mathrm{~kb} P$ st $\mathrm{I}-S a l \mathrm{I}$ fragment of $\mathrm{pRJ} 2034$ in the $P_{s t} \mathrm{I} / X$ hoI sites of $\mathrm{pRK} 290 \mathrm{pol} 2$ & This work \\
\hline
\end{tabular}

are thermolabile homodimers of $M_{\mathrm{r}} 120000(2 \times 60000)$ carrying an $\mathrm{Fe}-\mathrm{S}$ cluster, and include the highly homologous products of the Escherichia coli fumA (Miles $\&$ Guest, 1984) and fumB genes (Bell et al., 1989) and probably also an immunologically related fumarase of Euglena gracilis (Shibata et al., 1985; Woods et al., 1988b). Class II fumarases are thermostable homotetramers of $M_{\mathrm{r}} 200000(4 \times 50000)$. This class includes the structurally related products of the $E$. coli fum $C$ (Woods et al., 1986), Bacillus subtilis citG (Moir et al., 1984; Miles \& Guest, 1985) and Saccharomyces cerevisiae FUMI genes (Wu \& Tzagoloff, 1987), and of the human liver (Kinsella \& Doonan, 1986), rat liver (Suzuki et al., 1989) and porcine heart (Sacchettini et al., 1988) fumarase genes. In fact, all animal fumarases characterized to date exhibit the biochemical properties characteristic of class II fumarases. E. coli appears to be the only proven case for the presence of both class I and class II fumarases in one and the same organism.
Here we report the cloning, sequencing and mutational analysis of the fumarase gene (fumC) from the soybean root nodule bacterium $B$. japonicum. Contrary to our expectations, the $B$. japonicum fum $C$ mutant strain was not affected in symbiotic nitrogen fixation. This led to the discovery of a second fumarase activity that could functionally substitute for the missing FumC protein.

\section{Methods}

Bacterial strains, vectors and recombinant plasmids. These are listed in Table 1. B. japonicum strain $110 s p c 4$ is a spectinomycin-resistant derivative of strain 3I1 b1 10 (US Department of Agriculture, Beltsville, MD, USA) and is called 'wild type' throughout this paper. Strain FC5 is a chromosomal fumC deletion mutant of the wild-type in which two fum $C$-internal $S p h \mathrm{I}$ fragments have been replaced by a $\mathrm{Km}^{\mathrm{R}}$ fragment. $E$. coli strain $\mathrm{JH} 400$ is deleted for fum $A$, fumB and fumC. Plasmid pGS210 carries the $E$. coli fumC gene in $\mathrm{pUC12}$ in the opposite orientation to the lac gene in the vector. The plasmids used to transform strain JH400 were first isolated from strain JM109 $\left(\mathrm{r}^{-}, \mathrm{m}^{+}\right)$. 


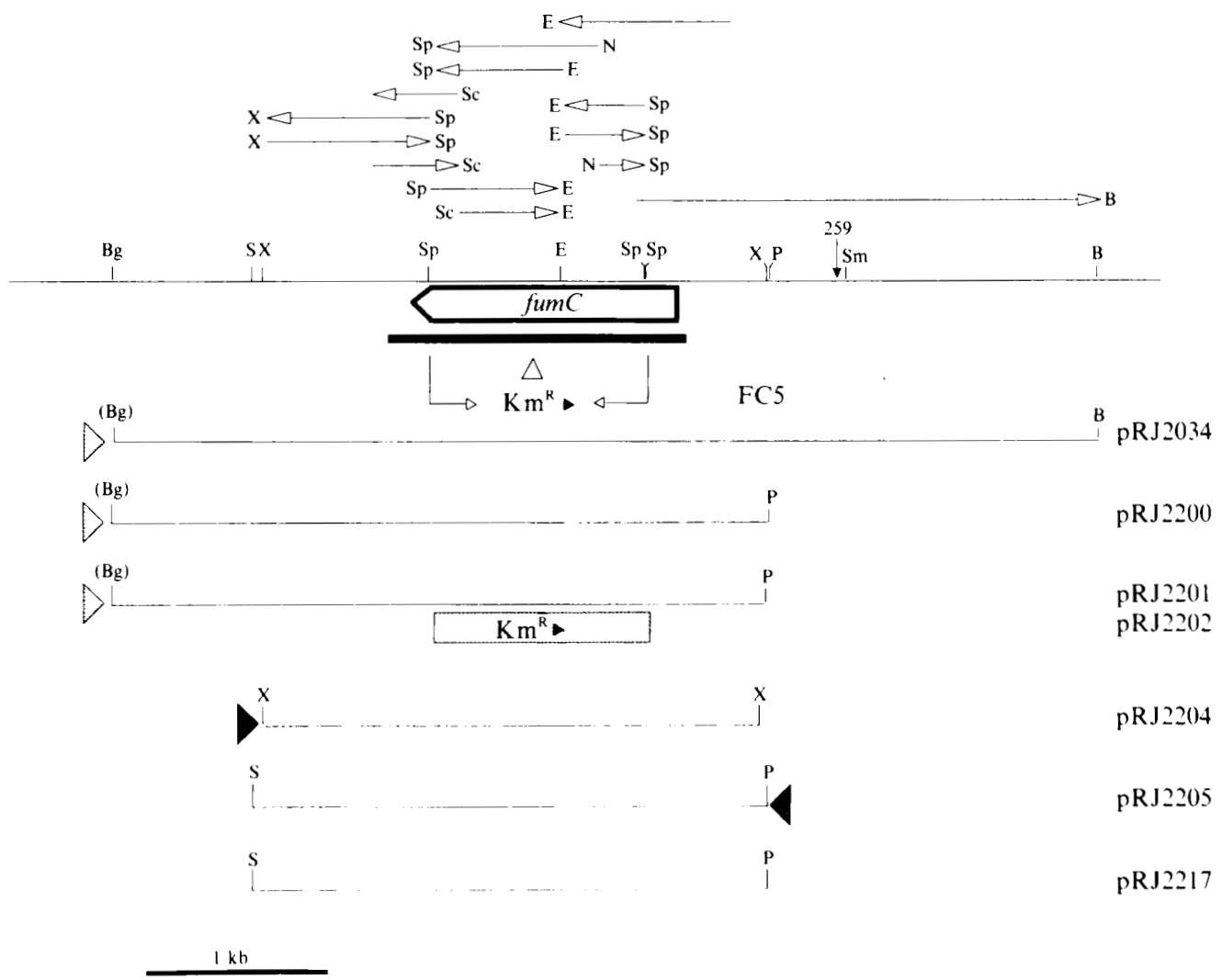

Fig. 1. Restriction map of the $B$. japonicum wild-type DNA region containing fum $C$. The map also shows the Tn 5 insertion site in mutant 259 (vertical arrow). The bold line below fum $C$ indicates the sequenced region shown in Fig. 2, which was established by sequencing the MI 3 subclones shown above the map. The open arrows mark the $S p h I$ fragments deleted and replaced by a kanamycin resistance $\left(\mathrm{Km}^{\mathrm{R}}\right)$ gene in mutant FC5. In the plasmid constructs below the map, the shaded and filled arrowheads denote the positions and directions of the lac and tac promoters, respectively. The shaded box represents the DNA fragment carrying the kanamycin resistance gene. Abbreviations: B, BamHI; Bg, BglII; (Bg), Bg/II site lost after cloning; E, EcoRI; N, NsiI; P, PstI; S, SalI; Sc, SacI; Sm, SmaI ; Sp, SphI: X, Xhol.

Construction of the fumC mutant. B. japonicum mutant 259 was found after screening several thousand mutants generated by random $\operatorname{Tn} 5$ mutagenesis for a $\mathrm{Nod}^{+}$and $\mathrm{Fix}^{-}$phenotype. The Tn5-mutagenized region of mutant 259 was cloned from total DNA, and used as a hybridization probe to find the corresponding wild-type region in a cosmid library (Regensburger, 1986). A $5.5 \mathrm{~kb} \mathrm{BamHI-Bg/II} \mathrm{fragment}$ of the cosmid clone pL20-11H containing the Tn5 insertion site was cloned in the Bam HI site of pUC 19, resulting in plasmid pRJ2034 (Fig. 1). For the purpose of constructing the SphI deletion in fumC, the PstI fragment of pRJ2034 containing fumC was first subcloned in the PstI site of pBLS(KS)+. The resulting clone, pRJ2200 (Fig. 1), carried fum $C$ in the opposite orientation to the lac gene of the vector. Plasmid pRJ2200 was then digested with SphI, treated with T4 DNA polymerase to generate blunt ends, and ligated to the SmaI fragment of pUC4-KIXX containing the $\mathrm{Km}^{\mathrm{R}}$ gene. The orientation of the $\mathrm{Km}^{\mathrm{R}}$ gene in the resulting plasmid, pRJ2201, is opposite to that of fumC (Fig. 1). The EcoRI-BamHI fragment of pRJ2201 containing the mutated region was finally subcloned in $\mathrm{pSUP} 202$ digested with EcoRI and Pst I. To achieve this, the BamHI site of the insert and the Pst site of the vector were treated with Klenow and T4 DNA polymerases, respectively, to generate blunt ends. The final construct, pRJ2202 (Fig. 1), was transferred into $B$. japonicum by conjugation. Exconjugants in which a double crossover recombination event had occurred were selected for $\mathrm{Km}^{\mathrm{R}} \mathrm{Cm}^{\mathrm{R}}$, and screened for loss of $\mathrm{Tc}^{\mathrm{R}}$. The correct genomic structure of the deletion mutation in strain FC5 was confirmed by appropriate Southern blot hybridizations (not shown).
Construction of complementing plasmids. The plasmid pRJ2204 was constructed by cloning the $2.7 \mathrm{~kb}$ Xhol fragment of pRJ2034 (Fig. 1) in the $S a l I$ site of the expression vector pJF118EH, which carried the $t a c$ promoter as well as the lacl $^{\mathrm{q}}$ repressor gene. The orientation of the fumC gene in this construct was opposite to the tac promoter. In pRJ2205 (Fig. 1) the $3.7 \mathrm{~kb} \mathrm{Bam} \mathrm{HI-HindIII} \mathrm{fragment} \mathrm{of} \mathrm{pRJ2200} \mathrm{was}$ cloned in the $B a m \mathrm{HI} /$ HindIII sites of $\mathrm{pJF} 118 \mathrm{EH}$ so that fumC was under the control of the tac promoter. Plasmid pRJ2217 was constructed by cloning the fumC-containing $P_{s t}$-SalI fragment of pRJ2034 in the vector pRK290pol2 digested with Pst I and XhoI. The orientation of fum $C$ in this clone was the same as the $T_{c^{R}}$ gene of the vector.

Media and growth conditions. B. japonicum was grown aerobically in PSY medium (Regensburger \& Hennecke, 1983) and anaerobically in

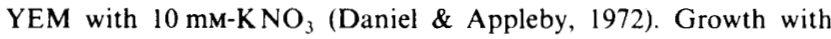
different carbon sources was tested in aerobic liquid cultures in modified H-M medium (Cole \& Elkan, 1973). The modification consisted in adding $\mathrm{K}^{+}$ions to the medium by replacing $0.12 \mathrm{~g}$ $\mathrm{NaH}_{2} \mathrm{PO}_{4} 1^{-1}$ with $0.6 \mathrm{~g} \mathrm{NaH} \mathrm{PO}_{4} / \mathrm{K}_{2} \mathrm{HPO}_{4} 1^{-1}$. Carbon sources (succinate, fumarate, L-malate, L-glutamate, and L-aspartate) were added to a final concentration of $20 \mathrm{~mm}$. The $E$. coli strains were grown in complex LB medium or in M9 minimal medium (Miller, 1972). The complementation assay of the $E$. coli Fum- strain $\mathrm{JH} 400$ was done in aerobic liquid M9 salts medium (Miller, 1972) supplemented with $40 \mu \mathrm{g}$ methionine $\mathrm{ml}^{-1}$, and using $40 \mathrm{~mm}$-fumarate as carbon source. Ampicillin $\left(200 \mu \mathrm{g} \mathrm{ml}^{-1}\right)$ was added for plasmid selection. 
Bacterial crosses. The pSUP202-derived plasmids were transferred into $B$. japonicum by conjugation using $E$. coli $\mathrm{S} 17-1$ as donor (Simon $e t$ al., 1983). The pRK290pol2-based plasmid or the vector itself were transferred from E. coli $\mathrm{HB} 101$ to $B$. japonicum by tri-parental matings using the helper plasmid pRK2013, which provided the transfer functions in trans (Ditta et al., 1980).

Symbiotic nitrogen fxation assay. The symbiotic nitrogen fixation (Fix) activity of the $B$. japonicum wild-type and mutant strains was tested in soybean plant infection tests as described previously (Hahn \& Hennecke, 1984). Acetylene reduction (Turner \& Gibson, 1980) was measured in 20-d-old plants.

DNA work. Cloning, restriction endonuclease digests, plasmid isolations, transformations, Southern blots, and hybridizations were performed using standard protocols (Maniatis et al., 1982). Radioactive labelling of DNA probes was done by random priming (Feinberg \& Vogelstein, 1984). The fumC DNA was sequenced on both strands using overlapping M13 clones prepared by Bal31 nuclease deletions and by subcloning restriction fragments. The sequencing strategy is depicted at the top of Fig. 1. The sequencing reactions (Sanger $e t$ al., 1977) were performed using M13-specific fluorescent dye primers and the method and equipment for automated DNA sequencing (Applied Biosystems Sequencer model 370).

Analysis of the sequences determined. The analysis of the DNA sequences, as well as data bank searches, protein sequence comparisons and alignments were performed with the GCG sequence analysis software package release 6.2 (University of Wisconsin, Madison, WI, USA).

Enzymology. Crude cell extracts of B. japonicum were prepared from cultures grown to stationary phase. The cells were collected and washed three times with sodium phosphate buffer $(100 \mathrm{~mm}, \mathrm{pH} 7 \cdot 3)$. The cells were then disrupted by passing them twice through a French pressure cell ( $124 \mathrm{MPa}$ ). The lysate was centrifuged at $30000 \mathrm{~g}$ for $30 \mathrm{~min}$ and the supernatant was used for the enzyme assays. Fumarase activity was measured at $25^{\circ} \mathrm{C}$ by monitoring the production of fumarate from Lmalate as the increase in absorbance at $250 \mathrm{~nm}$ (Hill \& Bradshaw, 1969). Activities were expressed as $\mu$ mol fumarate $\mathrm{min}^{-1}$ (mg protein) $)^{-1}$ using a value of $1479 \mathrm{M}^{-1} \mathrm{~cm}^{-1}$ for the absorption coefficient of fumarate at $\mathrm{pH} 7.3$ and $250 \mathrm{~nm}$ (O.Hare \& Doonan, 1985). Mesaconase activity was measured at $25^{\circ} \mathrm{C}$ using the same conditions as described for the fumarase assay but using DL-citramalate (100 mM) as substrate. Protein concentrations were determined as described by Bradford (1976).

\section{Results}

Identification and sequencing of the B. japonicum fumC gene

The fum $C$ gene was found fortuitously in the course of studying a $B$. japonicum Tn5 mutant (strain 259) that was reported to have a pleiotropic defect in nodule development and symbiotic nitrogen fixation (Regensburger et al., 1986). The genomic region containing the Tn5 mutation of strain 259 was cloned as described in Methods. DNA sequence analysis of a region located about $1 \mathrm{~kb}$ adjacent to the mapped $\operatorname{Tn} 5$ insertion site revealed the existence of an open reading frame (ORF) that was identified as fumC (see text below and Fig. 1). Whilst the independent genetic characterization of mutant 259 was still in progress (Ebeling, 1990) we became interested in a more detailed characterization of fum $C$. In particular it was thought that the construction of a fumC mutant could provide a means to further substantiate the importance of $\mathrm{C}_{4}$-dicarboxylate metabolism and the TCA cycle for symbiotic nitrogen fixation in B. japonicum.

A restriction map of the cloned region with the location of the fum $C$ gene and the sequencing strategy are shown in Fig. 1. A 1647 bp DNA sequence is shown in Fig 2. This sequence contained the 1461 bp fumC ORF that started at nucleotide 22. The ATG at this position was arbitrarily chosen as the fum $C$ start codon because it was preceded by a well-conserved $E$. coli-like ShineDalgarno sequence, 5'-GAGGAG-3' (Shine \& Dalgarno, 1975). However, it should be noted that there are other potential start codons at the beginning of fumC (Fig. 2). The predicted amino acid sequence of the fum $C$-encoded protein is also shown in Fig. 2; it consisted of 487 amino acids and had a calculated $M_{\mathrm{r}}$ of 52650 . Protein sequence comparisons revealed that the FumC polypeptide had a high degree of similarity $(72-76 \%$ ) to fumarases of class II (Fig. 3). The percentage of identical amino acids between the $B$. japonicum FumC protein and all others aligned in Fig. 3 ranged from $53 \%$ to $64 \%$. There was also a weaker, but significant homology to aspartase sequences from $E$. coli W $(39 \%$ identity, $60 \%$ similarity; Takagi et al., 1985) and Pseudomonas fluorescens (44\% identity, 64\% similarity; Takagi et al., 1986 b) (not shown).

\section{Complementation of an E. coli Fum- mutant with the $B$. japonicum fum $C$ gene}

The B. japonicum fum $C$ gene was tested for its ability to complement the Fum ${ }^{-}$phenotype of $E$. coli JH400. This mutant strain carried deletions in all three fumarase genes (Table 1). The strain was transformed with different plasmids, carrying either the $B$. japonicum fum $C$ gene (pRJ2200, pRJ2204 and pRJ2205, see Fig. 1), the $E$. coli fumC gene (pGS210), or just the vector (pJF118EH). The transformants were tested for growth in minimal medium with fumarate as carbon source. Those transformants that carried a pJF118EH-based plasmid (i.e. pRJ2204 and pRJ2205) or the vector itself were also tested in the presence of $1 \mathrm{mM}-\mathrm{IPTG}$ to allow induction of transcription from the tac promoter located on the vector. Only pRJ2205 in the presence of IPTG and pGS210 (the positive control) were capable of complementing the aerobic Fum $^{-}$phenotype of JH400. This result indicated that the $B$. japonicum fum $C$ gene, upon induction by a functional $E$. coli promoter, could be expressed in $E$. coli to produce an active fumarase capable of restoring the $\mathrm{Fum}^{-}$phenotype of strain JH400. 


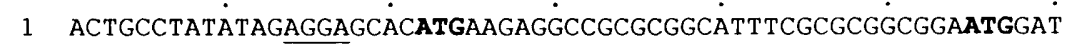

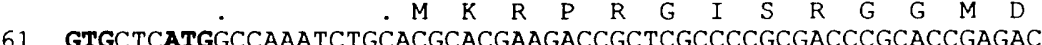
$\begin{array}{llllllllllllllllllllllllll}V & \mathrm{~L} & \mathrm{M} & \mathrm{A} & \mathrm{K} & \mathrm{S} & \mathrm{A} & \mathrm{R} & \mathrm{T} & \mathrm{K} & \mathrm{T} & \mathrm{A} & \mathrm{R} & \mathrm{P} & \mathrm{A} & \mathrm{T} & \mathrm{R} & \mathrm{T} & \mathrm{E} & \mathrm{T}\end{array}$

121 GACAGTTTCGGTCCCATCGÄGGTCCCCTCCंGATCGCTATTGGGGCGCGCÄGACCGAACGं $\begin{array}{llllllllllllllllllll}D & S & F & G & \text { P } & \text { I } & \text { E } & \text { V } & \text { P } & \text { S } & \text { D } & \text { R } & \text { Y } & \text { W } & \text { G } & \text { A } & \text { Q } & \text { T } & \text { E } & \text { R }\end{array}$

181 TCGCGGCAGAATTTCCGCATCGGCACGGATCGCATGCCGÄCTCGCTCGT $\frac{S p h I}{\operatorname{SCATGCGCTC}}$ $\begin{array}{llllllllllllllllllllll}S & R & Q & N & F & R & I & G & T & D & R & M & P & I & S & L & V & H & A & L\end{array}$

241 GGCATCGTCAAGCTCGCCGCGGCGCAGTCCAACCGCGAGCTCGGCCTGCTCGACCAGCGC $\begin{array}{lllllllllllllllllllll}G & I & V & K & L & A & A & A & Q & S & N & R & E & L & G & L & L & D & Q & R\end{array}$

301 CGCGCCAGTGCCATCATCCG̈GCCGCGCGC̈GAGGTATCGÁCGGCAGACCTCGACGATCA $\begin{array}{llllllllllllllllllllll}R & A & S & A & I & I & R & A & A & R & E & V & S & T & A & D & L & D & D & H\end{array}$

361 TTCCCGCTCGTCGTGTGGCÄGACCGGCTCGंGGCACGCAGACCAACATGAACCTCAACGÁ $\begin{array}{llllllllllllllllllll}F & P & L & V & V & W & Q & T & G & S & G & T & Q & T & N & M & N & L & N & E\end{array}$

421 GTGATCGCCAACCGCGCCAAंTGAGCTGCTCंGGCGGCGAGCTCGGCGCCAÁGAAGCCGGTG $\begin{array}{lllllllllllllllllllllll}\mathrm{V} & \text { I } & A & N & R & A & N & E & \text { L } & \text { L } & G & G & E & \text { L } & G & A & K & K & P & V\end{array}$

481 CATCCGAACGATCACGTCAACATGAGCCAGTCGTCGAACGACTCTTTTCCCACCGCAATG $\begin{array}{llllllllllllllllllll}\mathrm{H} & \mathrm{P} & \mathrm{N} & \mathrm{D} & \mathrm{H} & \mathrm{V} & \mathrm{N} & \mathrm{M} & \mathrm{S} & \mathrm{Q} & \mathrm{S} & \mathrm{S} & \mathrm{N} & \mathrm{D} & \mathrm{S} & \mathrm{F} & \mathrm{P} & \mathrm{T} & \mathrm{A} & \mathrm{M}\end{array}$

541 CATATCGCGGCGGCTAGCCGCATCACCGCCGATCTCGTTCCTGCCCTTGGCGAACTGCTC $\begin{array}{lllllllllllllllllllll}\text { H } & \text { I } & \text { A } & \text { A } & \text { A } & \text { S } & \text { R } & \text { I } & \text { T } & \text { A } & \text { D } & \text { L } & \text { V } & \text { P } & \text { A } & \text { L } & \text { G } & \text { E } & \text { L } & \text { L }\end{array}$

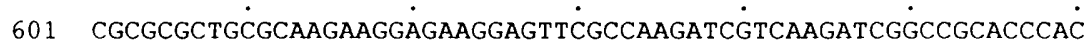
$\begin{array}{llllllllllllllllllll}R & A & L & R & K & K & E & K & E & F & A & K & I & V & K & I & G & R & T & H\end{array}$

661 ACCCAGGACGCGACGCCGCTGACGCTCGGCCAGGAATTCTCCGGCTATGCCGCGCAGGTC $\begin{array}{lllllllllllllllllllll}T & Q & D & A & T & \text { P } & \text { L } & \text { T } & \text { L } & G & Q & E & F & \text { S } & \text { G } & \text { Y } & \text { A } & \text { A } & Q & \text { V }\end{array}$

721 GAACGCGGGÁTCGCGCGACTGAAGGTCGCGGTGAAGGAGC'TCTATCCGCTGGCGCAGGGCं $\begin{array}{llllllllllllllllllll}E & R & G & I & A & R & L & K & V & A & \text { V } & \text { K } & \text { E } & \text { L } & \text { Y } & \text { P } & \text { L } & \text { A } & \text { Q } & G\end{array}$

781 GGCACCGCCGTCGGCACCGGCCTCAACGCGAAGCCGCGCTTTGCAAGACTGTTCGCAAÁ $\begin{array}{llllllllllllllllllll}G & T & A & V & G & T & G & \text { L } & \text { N } & \text { A } & \text { K } & \text { P } & \text { R } & \text { F } & \text { A } & \text { R } & \text { L } & \text { F } & \text { A } & \text { K }\end{array}$

841 CACGTTGCCGGAATCACCAAACTGCCCTTCACCAGCGCCGCCAACAAATTCGAGGCGCTG $\begin{array}{llllllllllllllllllll}\text { H } & \text { V } & \text { A } & G & \text { I } & \text { T } & \text { K } & \text { L } & \text { P } & \text { F } & \text { T } & \text { S } & \text { A } & \text { A } & \text { N } & \text { K } & \text { F } & \text { E } & \text { A } & \text { L }\end{array}$

901 GCCTCGAACGATGCTTATGTGCTGGCGCAC̈GGCGCCATCÁGTTCGGTCGCGACAGGCCTG $\begin{array}{llllllllllllllllllllll}\text { A } & S & N & D & A & Y & V & \text { L } & \text { A } & \text { H } & G & \text { A } & \text { I } & \text { S } & \text { S } & \text { V } & \text { A } & \text { T } & G & \text { L }\end{array}$

961 TTCAAGATCGCCAACGACATCCGCCTGCTCंGGATCGGGTCंCGCGCTCAGG̈GCTCGGCGÁ $\begin{array}{llllllllllllllllllll}\mathrm{F} & \mathrm{K} & \mathrm{I} & \mathrm{A} & \mathrm{N} & \mathrm{D} & \mathrm{I} & \mathrm{R} & \mathrm{L} & \mathrm{L} & \mathrm{G} & \mathrm{S} & \mathrm{G} & \mathrm{P} & \mathrm{R} & \mathrm{S} & \mathrm{G} & \mathrm{L} & \mathrm{G} & \mathrm{E}\end{array}$

1021 CTGATCCTGCCGGAGAACGAACCGGGCTCGTCGATCATGCCGGGCAAGGTCAATCCGACG $\begin{array}{llllllllllllllllllllll}L & I & L & P & E & N & E & P & G & S & S & I & M & P & G & K & V & N & P & T\end{array}$

1081 CAGTGCGAGGCGATGACCAंTGTGTGCTGCCAGGTGTTCGGCAATCACACCGCGATCACG $\begin{array}{lllllllllllllllllllll}Q & C & E & A & M & T & M & \text { V } & C & C & Q & V & F & G & N & H & T & A & I & T\end{array}$

1141 GTCGCCGGCAGCCAGGGCCÁTTTCGAGCTCAACGTCTACÁAGCCCGTGCTGGCCTACAAC $\begin{array}{lllllllllllllllllllll}V & A & G & S & Q & G & H & F & E & \text { L } & N & \text { V } & \text { Y } & \text { K } & \text { P } & \text { V } & \text { L } & \text { A } & \text { Y } & \text { N }\end{array}$

1201 ATGCTGCACTCGATCCGCCTGATGGCCGATGCCGCGCGCTCCTTCACCGAACATTGCGTC $\begin{array}{llllllllllllllllllll}M & L & H & S & I & R & L & M & A & D & A & A & R & S & F & T & E & H & C & V\end{array}$

1261 AGCGGCATCCGCGCCGACGAAAAGCGCATÁAGTGAGCTGÁTGCAGCGCTCGGCTGATGCT'́ $\begin{array}{llllllllllllllllllll}S & G & I & R & A & D & E & K & R & I & S & E & L & M & Q & R & S & L & M & L\end{array}$

1321 GTGACCGCGCंTCGCACCGAÄGATCGGCTACGACAACGCCGCCAAGGTCGCंGAAGACGGC $\dot{\bar{G}}$ $\begin{array}{llllllllllllllllllll}V & \mathrm{~T} & \mathrm{~A} & \mathrm{~L} & \mathrm{~A} & \mathrm{P} & \mathrm{K} & \mathrm{I} & \mathrm{G} & \mathrm{Y} & \mathrm{D} & \mathrm{N} & \mathrm{A} & \mathrm{A} & \mathrm{K} & \mathrm{V} & \mathrm{A} & \mathrm{K} & \mathrm{T} & \mathrm{A}\end{array}$ $\operatorname{SphI}$

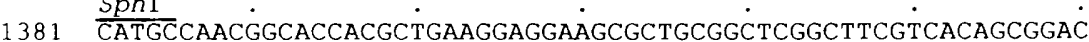
$\begin{array}{llllllllllllllllllll}H & A & N & G & T & T & L & K & E & E & A & L & R & L & G & F & V & T & A & D\end{array}$

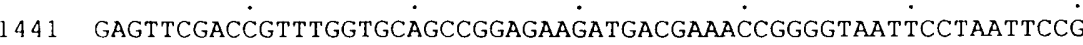
$\begin{array}{llllllllllllllllll}E & F & D & R & L & V & Q & P & E & K & M & T & K & P\end{array}$

1501 ATAGTCATCCGTAATGATACGGAGCCAAAAAGCTCATAA TंTGTAAGGCT TAAAGGAGAGG

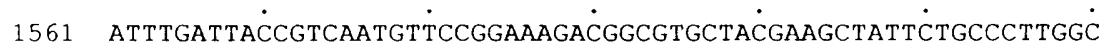
ATTTGATTACCGTCAATGTTCCGGAAAGACGGC
GGGGCGAAATTCATCGTTTGATGGCCA 1647
Fig. 2. DNA sequence containing the ORF of the fumC gene. The predicted amino acid sequence of the FumC protein is also shown. A presumptive ribosome binding site upstream of the first ATG is underlined. Four possible translational starts are emphasized in bold letters. The $S p h$ I sites used to construct the deletion are overscored. 
MKRPRGISRG GMDVLMAKSA RTKTARPATR TETDSFGPIE VPSDRYWGAO TERSRONFRI G. TDRMPIS LVHALGIVKI AAAOSNRELG LLDQRRASAI MNTVR SEKDSMGAID VPADKLWGAQ TQRSLEHFRI ..STEKMPTS LIHALALTKR AAAKVNEDLG LLSEEKASAI

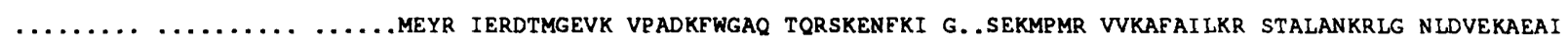
MLRFTNCSC KTFVKSSYKL NIRRMNSSFR TETDAFGEIH VPADKYWGAQ TQRSFQNFKI GGARERMPLP LVHAFGVLKK SAAIVNESLG GLDPKISKAI $\ldots \ldots \ldots \ldots \ldots \ldots \ldots$. . MASQNSFR IEYDTFGELK VPNDKYYGAQ TVRSTMNFKI GGVTERMPTP VIKAFGILKR AAAEVNQDYG . LDPKIANAI $\ldots \ldots \ldots \ldots \ldots \ldots \ldots$. . ASQNSFR IEYDTFGELK VPTDKYYGAQ TVRSTMNFKI GGATERMPIP VIKAFGILKR AAAEVNQEYG . LDPKIASAI $\ldots \ldots \ldots \ldots \ldots \ldots \ldots \ldots$.............. 101

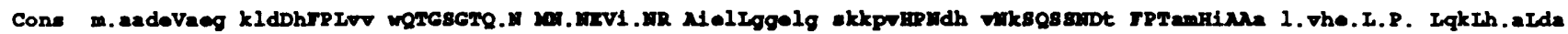
BjFUmC IRAAREVSTA DLDDHFPLVV WQTGSGTQTN MNLNEVIANR ANELLGGELG AKKPVHPNDH VNMSQSSNDS FPTAMHIAAA SRITADLVPA LGELLRALRK ECFUMC RQAADEVLAG QHDDEFPLAI WQTGSGTQSN MNMNEVLANR ASELLGGVRG MERKVHPNDD VNKSQSSNDV FPTAMHVAAL LALRKQLIPQ LKTLTQTLNE BSC1TG AAVCDDVLKG KYDDNFPLVV WQTGSGTQSN MNMNEVVANR ATALLKEKNS DQTI.HPNDD VNRSQSSNDT FPTAMHVAAV LAVYEQLVPA LDQLRNTLDE SCFUm1 QQAADEVASG KLDDHFPLVV FQTGSGTQSN MNANEVISNR AIEILGGKIG SKQV. HPNNH CNQSQSSNDT FPTVVHIAAS LQIQNELIPE LTNLKNALEA HUMFUm MKAADEVAEG KLNDHFPLVV WQTGSGTQTN MNVNEVISNR AIEMLGGELG SKIPVHPNDH VNKSQSSNDT FPTAMHIAAA IEVHEVLLPG LQKLHDALDA Rat Fum PigFum MKAADEVAEG KLNDHFPLVV WOTGSGTQTN MNVNEVISNR AIEMLGGELG SKKPVHPNDH VNKSQSSNDT FPTAMHIAAA LEVHQVLLPG LQKLHDALSA MKAADEVAEG KLNDHFPLVV WQTGSGTQTN MNVNEVISNR AIEMLGGELG SKKPVHPNDH VNKSQSSNDT FPTAMHIAAA VEVHEALLPG LQKLHDALDA 201

Kekefa.ivK IGRTH. QDAt PLTLGQIfsG yvqqve...e rikaa.pr.y eIAqGGTAvG TGlwt.pgfa ekva..va.l TglpTvtapN kreALaahDa KEKEFAKIVK IGRTHTQDAT PLTLGQEFSG YAAQVERGIA RLKVAVKELY PLAQGGTAVG TGLNAKPRFA RLFAKHVAGI TKLPETSAAN KFEALASNDA KSRAFADIVK IGRTHLQDAT PLTLGQEISG WVAMLEHNLK HIEYSLPHVA ELALGGTAVG TGLNTHPEYA RRVADELAVI TCAPFVTAPN KFEALATCDA KAKAYNDIVK IGRTHLQDAT PLTLGQEISG WVHMLDRSKE MILEATDKMR ALAIGGTAVG TGINAHPEFG ELVSEEITKL TGQTFSSSPN KFHALTSHDE KSKEFDHIVK IGRTHLQDAT PLTLGQEFSG YVQQVENGIQ RVAHSLKTLS FLAQGGTAVG TGLNTKPGFD VKIAEQISKE TGLKFQTAPN RFEALAAHDA KSKEFAQIIK IGRTHTQDAV PLTLGQEFSG YVQQVKYAMT RIKAAMPRIY ELARGGTAVG TGLNTRIGFA EKLAAKVAAL TGLPFVTAPN KFEALAAHDA KSKEFAQVIK IGRTHTQDAV PLTLGQEFSG YVQQVQYAME RIKAAMPRIY ELAAGGTAVG TGLNTRIGFA EKVAAKVAAL TGLPFVTAPN KFEALAAKDA KSREFAQIIK IGRTHTQDAV PLTLGQEFSG YVQQVKYAIT RIKAAMPRIY ELAAGGTAVG TGLNTRIGFA EKVAAKVAAL TGLPFVTAPN NFEALAAHDA 301

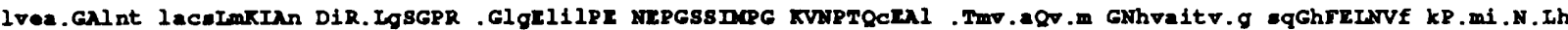
YVLAHGAISS VATGLFKIAN DIRLLGSGPR SGLGELILPE NEPGSSIMPG KVNPTQCEA. MTMVCCQV.F GNHTAITVAG SQGHFELNVY KPVLAYNMLH LVQAHGALKG LAASLMKIAN DVRWLASGPR CGIGEISIPE NEPGSSIMPG KVNPTQCEAL .TMLCCQV.M GNDVAINMGG ASGNFELNVF RPMVIHNFLQ ITYAHGALKA LAADLMKIAN DVRWLASGPR CGIGEIVIPE NEPGSSIMPG KVNPTQSEAL .TMIAAQI.M GNDATIGEAA SQGNFELNVF KPVIIYNFLQ IVECSGALNT LACSLFKIAQ DIRYLGSGPR CGYHELMLPE NEPGSSIMPG KVNPTQNEAL .TQVCVQV.M GNNAAITFAG SQGQEELNVF KPVMIVNLLN LVELSGAMNT SSCSLMKIAN DIRFLGSGPR SGLGELILPE NEPGSSIMPG KVNPTQCEAA MTMVAAQV.M GNHVAVTVGG SNGHFELNVF KPMMIKNVLH LVELSGAMNT TACSLMKIAN DIRFLGSGPR SGLGELILPE NEPGSSIMPG KVNPTQCEA. MTMVAAQVCM GNHVAVTVGG SNGHFELNVF KPMMIKNVLH LVEHSGAMNT TACSLMKIAN DIRFLGSGPR SGLGELILPE NEPGSSIMPG KVNPTQCEAL TMVAAQV M GNHVAVTVGG SNGHFELNVF KPMMIKNVLH 401

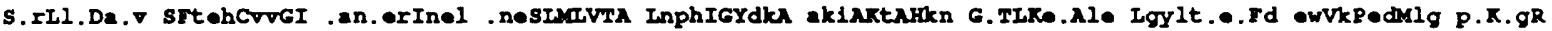
SIRLMADAAR SFTEHCVSGI RADEKRISEL MQRSLMLVTA LAPKIGYDNA AKVAKTAHAN GTTLKEEALR LGFVTADEFD RLVQPEKMT. . KPG SVRLLADGME SFNKHCAVGI EPNRERINQL LNESLMLVTA LNTHIGYDKA AEIAKKAHKE GLTLKAAALA LGYLSEAEFD SWVRPEQMVG SMKAGR SVQLLSDGMN SFHDKCAVGI EPNKETIQEN LSNSLMLVTA LNPHIGYENA AKIAKLAHKE GLTLKEAALK LELLTEEQFN EMVKPEDMVK P. KA SIRLITDAAY SFRVHCVEGI KANEPRIHEL LTKSLMLVTA LNPKIGYDAA SKVAKNAHKK GITLKESALE LGVLTEKEFD EWVVPEHMLG P.K SARLLGDASV SFTENCVVGI QANTERINKL MNESLMLVTA LNPHIGYDKA AKIAKTAHKN GSTLKETAIE LGYLTAEQFD EWVKPKDMLG P.K SARLLGDASV SFTENCVVGI QANTERINKL MNESLMLVTA LNPHIGYDKA AKIAKTAHKN GSTLKKTAIE LGYLTAEQFD EWVKPKDMLG P.K SARLLGDAAV SFTENCVVGI QANTERINKL MNESLMLVTA LNPHIGYDKA AKIAKTAHKN GSTLKATAVE LGYLTAEQFD EWVKPRDMLG P.K

Fig. 3. Amino acid sequence alignment of all available class II fumarases. The top sequence shows the consensus, in which the uppercase letters mean $100 \%$ conservation and the lower-case letters more than $50 \%$ conservation. The numbering system refers only to the amino acid arrangement in this figure and not to any of the sequences. The sequences were obtained from the following sources: EcFumC, E. coli FumC (Woods et al., 1986); BsCitG, B. subtilis CitG (Miles \& Guest, 1985); ScFuml, S. cerevisiae Fuml (Wu \& Tzagoloff, 1987); HumFum, human liver fumarase (Kinsella \& Doonan, 1986); RatFum, rat liver fumarase (Suzuki et al., 1989); PigFum, porcine heart fumarase (Sacchettini et al., 1988). 
Table 2. Fumarase activity in $B$. japonicum strains

Fumarase activities are expressed in $\mu$ mol fumarate $\min ^{-1}(\mathrm{mg} \text { protein })^{-1}$. Heat treatment was carried out at $52^{\circ} \mathrm{C}$.

\begin{tabular}{lcccc}
\hline \hline Strain (plasmid) & $\begin{array}{c}\text { Specific } \\
\text { activity }\end{array}$ & $\begin{array}{c}\text { Percentage of } \\
\text { wild-type } \\
\text { activity }\end{array}$ & $\begin{array}{c}\text { Specific activity } \\
\text { after heat treatment }\end{array}$ & $\begin{array}{c}\text { Percentage of } \\
\text { wild-type } \\
\text { activity }\end{array}$ \\
\hline Wild-type & $0 \cdot 16$ & 100 & $0.08(10 \mathrm{~min})$ & 50 \\
& & & $0.05(50 \mathrm{~min})$ & 31 \\
FC5 & $0 \cdot 09$ & 56 & $0.00(10 \mathrm{~min})$ & 0 \\
Wild-type (pRJ2217) & 0.79 & 493 & NT & NT \\
Wild-type (pRK290pol2) & $0 \cdot 14$ & 88 & NT & NT \\
FC5(pRJ2217) & $0 \cdot 37$ & 230 & NT & NT \\
FC5(pRK290pol2) & $0 \cdot 06$ & 37 & NT & NT \\
\hline \hline
\end{tabular}

NT, Not tested.

\section{Phenotypic analysis of the B. japonicum fumC deletion} mutant FC5

A B. japonicum fumC deletion mutant (strain FC5) was constructed by marker exchange as described in Methods. In the mutation two adjacent fumC-internal $S p h \mathrm{I}$ fragments ( $1149 \mathrm{bp}$ plus $19 \mathrm{bp}$ ) were replaced by a $1.2 \mathrm{~kb}$ SmaI fragment carrying a kanamycin resistance gene. The genotypic structure of the mutation is shown in Fig. 1. A plant infection test showed that the mutant FC5 had a $\mathrm{Nod}^{+} \mathrm{Fix}^{+}$phenotype in symbiosis with soybean. In free-living culture, strain FC5 was able to grow like the wild-type with all carbon sources tested (see Methods). Also, it grew anaerobically in YEM medium with nitrate as terminal electron acceptor.

The fumarase activities in crude extracts were determined for the wild-type and mutant FC5 grown aerobically in modified $\mathrm{H}-\mathrm{M}$ medium with $20 \mathrm{mM}$ succinate. The data obtained are summarized in Table 2. The fumarase activity in strain FC5 was $56 \%$ of that measured in the wild-type. This result suggested that fum $C$ coded for a fumarase that contributed more than $40 \%$ of the total fumarase activity present in $B$. japonicum grown under these conditions.

The previous reports that $E$. coli possessed two biochemically distinct types of fumarases that differed also in their thermal stabilities (Woods et al., 1988b) prompted us to test the fumarase activities of the $B$. japonicum wild-type and the mutant FC5 after heat treatment. The crude extract of strain FC5 had no detectable fumarase activity after a $10 \mathrm{~min}$ heat treatment at $52{ }^{\circ} \mathrm{C}$ (Table 2). By contrast, the extract from the wild-type retained $50 \%$ of its fumarase activity after $10 \mathrm{~min}$ incubation at $52{ }^{\circ} \mathrm{C}$, and even after $50 \mathrm{~min}$ incubation $31 \%$ fumarase activity was still detectable. This result provided evidence for the thermal stability of the $B$. japonicum FumC protein and the thermal instability of a second fumarase.

Mesaconase catalyses the interconversion of L-citramalate and mesaconate, but also has quite high fumarase activity due to its low substrate specificity. This enzyme was shown to function in the TCA cycle of Pseudomonas arvilla and Pseudomonas fluorescens (Oda et al., 1987). To test whether the postulated second fumarase activity observed in $B$. japonicum was to be ascribed to a mesaconase, $B$. japonicum was assayed for mesaconase activity (see Methods). No mesaconase activity, however, was detected in crude extracts of the wild-type. Furthermore, the fumarase activity proved to be specific for L-malate, as no activity could be detected when Dmalate was used as substrate in the assay. Pre-incubation of the crude extracts with $150 \mathrm{mM}$-D-malate resulted in a $50 \%$ inhibition of the fumarase activity (data not shown).

\section{Complementation of the B. japonicum fumC deletion mutant FC5}

To prove that the diminished fumarase activity observed in the fumC mutant was due to the mutation described, strain FC5 was complemented in trans with the wild-type fumC region cloned in the broad-host-range plasmid pRK290pol2. The strains carrying the complementing plasmid pRJ2217 (Fig. 1) showed about five-fold higher fumarase activities than the corresponding parent strains carrying either no plasmid or the vector alone (Table 2). This proved that the partial loss of fumarase activity observed in the mutant FC5 as compared to the wildtype was due to the fumC mutation described. The result also made it seem likely that the fumC promoter lay within the cloned fragment, thus allowing expression of the fumC gene. 


\section{Discussion}

The $B$. japonicum ORF described in this paper encodes a functional fumarase which, by analogy with the homologous gene in $E$. coli, was designated fumC. The evidence for this was based on (i) the similarity of the predicted amino acid sequence of the FumC protein to fumarases from other organisms, (ii) the ability of the fumC gene to complement the fumarase deficiency of an $E$. coli mutant, and (iii) the reduced fumarase activity observed in a $B$. japonicum fum $C$ deletion mutant.

\section{Sequence comparisons}

The high degree of amino acid sequence similarity between the $B$. japonicum FumC protein and other fumarases is typical for all class II fumarases. It is not clear whether the first 15 codons encoding the amino acids of the non-conserved $\mathrm{N}$-terminus of the predicted $B$. japonicum FumC sequence are translated. The amino acid sequence alignment shows that only $B$. japonicum FumC and $S$. cerevisiae Fuml have an extended $\mathrm{N}$ terminus. However, the $\mathrm{N}$-terminal sequence of Fuml was postulated to be involved in the transport of the protein from the cytoplasm into mitochondria and might not be present in the mature protein (Wu \& Tzagoloff, 1987). In the B. japonicum FumC protein the first 30 amino acids, up to the first conserved residue, do not have the characteristics of a signal peptide for membrane transport and, above all, there is no reason to believe that this enzyme is not cytoplasmic.

All class II fumarases, including B. japonicum FumC, share a high degree of homology with aspartases (Takagi et al., 1986a; Woods et al., 1986). Fumarases and aspartases catalyse analogous reactions, i.e. a hydration and amination of fumarate, respectively. These structural and functional similarities suggest a possible conservation in the active site of both enzymes (Woods et al., 1988b; Yumoto \& Tokushige, 1988). Structural and functional correlations with fumarases, aspartases and also the biochemically related argininosuccinase have been discussed by Woods et al. (1986, 1988a). Class I and class II fumarases are only marginally related, as seen from primary sequence comparisons and their biochemical properties. They show less than $6 \%$ sequence identity (Woods et al., 1988b), and their catalytic mechanisms are believed to be different (Yumoto \& Tokushige, 1988). Woods et al. $(1988 a, b)$ reported the only significant homology between these two fumarase classes: the sequence motif GS--IM--K-N--Q (around position 444 in Fig. 3, and around position 456 in E. coli FumA) is found within the largest stretch ( 18 residues) of identical amino acids in class II fumarases (Fig. 3) and also belongs to a well-conserved domain in all aspartases.
Alternative fumarase activity and physiological role of the fumarases

The presence of fumarase activity in the crude extracts from the $B$. japonicum fum $C$ deletion mutant FC5 led us to postulate the existence of a second fumarase, probably a class I type fumarase. E. coli possesses two of these fumarases: FumA and FumB. FumA accounts for about $80 \%$ of the fumarase activity when $E$. coli grows aerobically, whereas FumB is expressed only under anaerobic conditions and functions in the fermentative pathway that leads to the production of succinate (Yumoto \& Tokushige, 1988; Woods \& Guest, 1987). It seems unlikely that an obligate aerobe such as $B$. japonicum possesses a functional FumB homologue. Therefore, a FumA-homologous enzyme is more probably responsible for the observed thermolabile fumarase activity.

The existence of an alternative fumarase in $B$. japonicum explains why the fum $C$ mutant could grow in minimal medium with fumarate as sole carbon source. Similarly, assuming that a functional TCA cycle is essential in symbiosis, the $\mathrm{Fix}^{+}$phenotype of the FC5 mutant can now be explained by the existence of a second fumarase. In both physiological states this second fumarase was fully sufficient to phenotypically mask the fumC defect.

Prior to this study the only bacterium known to have more than one fumarase was $E$. coli. While the biological roles of the E. coli FumA and FumB proteins are now clear (see above), the role of the E. coli FumC protein has not yet been established. FumC accounts for up to $25 \%$ of the fumarase activity in aerobically grown $E$. coli cells. The respective gene is expressed under both aerobic and anaerobic conditions, and its weak promoter is not responsive to environmental changes (Woods \& Guest, 1987). The substrate affinity of the E. coli FumC protein, like that of FumA, is higher for fumarate than for L-malate, suggesting a role in the TCA cycle (Woods et al., 1988b).

The regulation of $B$. japonicum fumC expression also remains to be elucidated. The gene is expressed aerobically and contributes $40 \%$ or less (see above) of the total fumarase activity in aerobic cultures. The total fumarase specific activity measured here in free-living cultures of $B$. japonicum is equivalent to that reported for bacteroids isolated from root nodules of 18 -d-old plants (Karr et al., 1984). These authors showed that the fumarase activity in the bacteroids increased proportionally to the nitrogenase activity and reached a maximum of $0.35 \mu \mathrm{mol} \mathrm{min}{ }^{-1} \mathrm{mg}^{-1}$ at day 24 after infection. Similarly, Rhizobium leguminosarum MNF3841 bacteroids showed a threefold higher fumarase activity $\left(0.96 \mu \mathrm{mol} \mathrm{min} \mathrm{mi}^{-1} \mathrm{mg}^{-1}\right)$ as compared to chemostat 
cultures grown in fumarate $\left(0.29 \mu \mathrm{mol} \mathrm{min} \mathrm{mg}^{-1} \mathrm{mg}^{-1}\right)$ (McKay et al., 1989). From these studies it is evident that at least one of the two fumarases plays an important role during symbiosis and its activity may be regulated.

We thank J.R. Guest for providing us with E. coli strain JH400 and plasmid pGS210.

\section{References}

Bell, P. J., ANDrews, S. C., Sivak, M. N. \& Guest, J. R. (1989). Nucleotide sequence of the FNR-regulated fumarase gene ( $f u m B)$ of Escherichia coli K-12. Journal of Bacteriology 171, 3494-3503.

Bergersen, F. J. \& Turner, G. L. (1967). Nitrogen fixation by the bacteroid fraction of breis of soybean root nodules. Biochimica et Biophysica Acta 141, 507-515.

Bolton, E., Higgisson, B., Harrington, A. \& O'Gara, F. (1986). Dicarboxylic acid transport in Rhizobium meliloti: isolation of mutants and cloning of dicarboxylic acid transport genes. Archives of Microbiology 144, 142-146.

BOYER, H. W. \& Roulland-Dussorx, D. (1969). A complementation analysis of the restriction and modification of DNA in Escherichia coli. Journal of Molecular Biology 41, 459-472.

BRADFORD, M. M. (1976). A rapid and sensitive method for the quantification of microgram quantities of protein utilizing the principle of protein dye-binding. Analytical Biochemistry 72, 248253.

Cole, M. A. \& ElKan, G. H. (1973). Transmissible resistance to penicillin G, neomycin, and chloramphenicol in Rhizobium japonicum. Journal of Bacteriology 114, 248-253.

Daniel, A. M. \& APPLeBY, C. A. (1972). Anaerobic nitrate, symbiotic and aerobic growth of Rhizobium japonicum: effects on cytochrome P450, other hemoproteins, nitrate and nitrite reductases. Biochimica et Biophysica Acta 275, 347-354.

Ditta, G. S., Stanfield, S., Corbin, D. \& Helinski, D. R. (1980). Broad host range DNA cloning system for Gram-negative bacteria: construction of a gene bank of Rhizobium meliloti. Proceedings of the National Academy of Sciences of the United States of America 77, 7347-7351

DunCan, M. J. \& FraenKel, D. G. (1979). $\alpha$-Ketoglutarate dehydrogenase mutant of Rhizobium meliloti. Journal of Bacteriology 37, 415419.

EBELING, S. (1990) Entdeckung der nif $N$-, nifS- und frxA-Gene in Bradyrhizobium japonicum sowie Charakterisierung einer symbiontisch essentiellen RNA. Doctoral Thesis ETH No. 9108, Swiss Federal Institute of Technology, Zürich, Switzerland.

Engelke, Th., Jording, D., KapP, D. \& Pühler, A. (1989). Identification and sequence analysis of the Rhizobium meliloti dctA gene encoding the $\mathrm{C}_{4}$-dicarboxylate carrier. Journal of Bacteriology 171, 5551-5560

FEINBERG, A. P. \& VogeLsTeIN, B. (1984). Addendum. A technique for radiolabelling DNA restriction endonuclease fragments to high specific activity. Analytical Biochemistry 137, 266-267.

FigURSKI, D. H. \& HelinSKI, D. L. (1979). Replication of an origincontaining derivative of plasmid RK2 dependent on a plasmid function provided in trans. Proceedings of the National Academy of the United States of America 76, 1648-1652.

FinaN, T. M., WoOd, J. M. \& Jordan, D. C. (1983). Symbiotic properties of $\mathrm{C}_{4}$-dicarboxylic acid transport mutants of Rhizobium leguminosarum. Journal of Bacteriology 154, 1403-1413.

Fürste, J. P., Pansegrau, W., Frank, A., Blöcker, H., Scholz, P. \& Bagdasarian, M. (1986). Molecular cloning of the plasmid RP4 primase region in a multi-host-range tac $P$ expression vector. Gene $\mathbf{4 8}$, 119-131.

Gardiol, A., Arias, A., Cerveñansky, C. \& Martinez-Drets, G. (1982). Succinate dehydrogenase mutant of Rhizobium meliloti. Journal of Bacteriology 151, 1621-1623.
HaHN, M. \& HenNeCKe, H. (1984). Localized mutagenesis in Rhizobium japonicum. Molecular and General Genetics 193, 46-52.

HeNson, J. M., BlaKe, N. K. \& MaReK, L. (1987). The isolation of fumB mutants of Escherichia coli. Journal of General Microbiology 133, 2631-2638.

Hill, R. L. \& Bradshaw, R. A. (1969). Fumarase. Methods in Enzymology 13, 91-99.

HUMBECK, C. \& WERNER, D. (1988). Delayed nodule development in a succinate transport Tn5 mutant of Bradyrhizobium japonicum. In Nitrogen Fixation: Hundred Years After, p. 559. Edited by H. Bothe, F. J. de Bruijn \& W. E. Newton. New York: Gustav Fischer.

KarR, D. B., Waters, J. K., Susuki, F. \& Emerich, D. W. (1984). Enzymes of the poly- $\beta$-hydroxybutyrate and citric acid cycles of Rhizobium japonicum bacteroids. Plant Physiology 75, 1158-1162.

Kinsella, T. R. \& DoOnan, S. (1986). Nucleotide sequence of a cDNA coding for mitochondrial fumarase from human liver. Bioscience Reports 6, 921-929.

KURZ, W. G. W. \& LARUE, T. A. (1977). Citric acid cycle enzymes and nitrogenase in nodules of Pisum sativum. Canadian Journal of Microbiology 23, 1197-1200.

Maniatis, T., Fritsch, E. F. \& SAmbrook, J. (1982). Molecular Cloning: a Laboratory Manual. Cold Spring Harbor, NY: Cold Spring Harbor Laboratory.

MCKay, I. A., Dilworth, M. J. \& GlenN, A. R. (1989). Chemostat studies of carbon catabolism in Rhizobium leguminosarum MNF3841. Archives of Microbiology 152, 606-609.

Messing, J. (1983). New M13 vectors for cloning. Methods in Enzymology 101, 20-78.

MILES, J. S. \& GUEST, J. R. (1984). Complete nucleotide sequence of the fumarase gene fumA of Escherichia coli. Nucleic Acids Research 12, 3631-3642.

MiLes, J. S. \& Guest, J. R. (1985). Complete nucleotide sequence of the fumarase gene (citG) of Bacillus subtilis 168. Nucleic Acids Research $13,131-140$.

MilleR, J. H. (1972). Experiments in Molecular Genetics. Cold Spring Harbor, NY: Cold Spring Harbor Laboratory.

MoIr, A., Feavers, I. M. \& Guest, J. R. (1984). Characterization of the fumarase gene of Bacillus subtilis 168 cloned and expressed in Escherichia coli K12. Journal of General Microbiology 130, 3009-3017.

NorRander, J., KeMPE, T. \& MESSING, J. (1983). Construction of improved M13 vectors using oligonucleotide-directed mutagenesis. Gene 26, 101-106.

Oda, Y., SuZUKI, S. \& Katsuki, H. (1987). Physiological roles of two enzymes with fumarase activity in two pseudomonads. Biochemistry International 14, 871-878.

O'HaRe, M. C. \& Doonan, S. (1985). Purification and structural comparisons of the cytosolic and mitochondrial isoenzymes of fumarase from pig liver. Biochimica et Biophysica Acta 827, 127-134.

REgENSBURGER, B. (1986). Untersuchungen zur Regulation von Symbiose und Stickstoff-Fixierung in Bradyrhizobium japonicum: Charakterisierung von drei neuen Regulationsgenen. Doctoral Thesis ETH No. 8129, Swiss Federal Institute of Technology, Zürich, Switzerland.

REgensBurger, B. \& HENNECKe, H. (1983). RNA polymerase from Rhizobium japonicum. Archives of Microbiology 135, 103-109.

REGENSBURGER, B. \& HENNECKE, H. (1984). Free-living and symbiotic nitrogen fixing ability of Rhizobium japonicum is unaffected by rifampicin resistance mutations. FEMS Microbiology Letters 21, 7781.

Regensburger, B., Meyer, L., Filser, M., Weber, J., Studer, D., LAMB, J. W., FisCHER, H.-M., HAHN, M. \& HENNECKE, H. (1986) Bradyrhizobium japonicum mutants defective in root-nodule bacteroid development and nitrogen fixation. Archives of Microbiology 144, 355-366.

Robertson, J. G. \& TAYlor, M. P. (1973). Acid and alkaline invertases in roots and nodules of Lupinus angustifolius infected with Rhizobium lupini. Planta 112, 1-6.

Ronson, C. W., Lyttleton, P. \& Robertson, J. G. (1981). C - $^{-}$ dicarboxylate transport mutants of Rhizobium trifolii form ineffective nodules on Trifolium repens. Proceedings of the National Academy of Sciences of the United States of America 78, 4284-4288.

Sacchettini, J. C., Fraizier, M. W., Chiara, D. C., Banazak, L. J. \& Grant, G. A. (1988). Amino acid sequence of porcine heart 
fumarase. Biochemical and Biophysical Research Communications 153, 435-440.

Sanger, F., Nicklen, S. \& Coulson, A. R. (1977). DNA sequencing with chain-terminating inhibitors. Proceedings of the National Academy of Sciences of the United States of America 83, 765-773.

Shibata, H., Gardiner, W. E. \& Schwartzbach, S. D. (1985). Purification, characterization, and immunological properties of fumarase from Euglena gracilis var. bacillaris. Journal of Bacteriology 164, 762-768.

Shine, J. \& Dalgarno, L. (1975). Determinants of cistron specificity in bacterial ribosomes. Nature, London 254, 34-38.

Simon, A., Priefer, U. \& PÜHLer, A. (1983). Vector plasmids for in vivo and in vitro manipulation of Gram-negative bacteria. In Molecular Genetics of the Bacteria-Plant Interaction, pp. 98-106. Edited by A. Pühler. Berlin, Heidelberg, New York: Springer.

Stovall, I. \& Cole, M. (1978). Organic acid metabolism by isolated Rhizobium japonicum bacteroids. Plant Physiology 61, 787-790.

Suzuki, T., SATo, M., Yoshida, T. \& Tuboi, S. (1989). Rat liver mitochondrial and cytosolic fumarases with identical amino acid sequences are encoded from a single gene. Journal of Biological Chemistry 264, 2581-2586.

Takagi, J. S., Ida, N., Tokushige, M., Sakamoto, H. \& Shimura, Y. (1985). Cloning and nucleotide sequence of the aspartase gene of Escherichia coli W. Nucleic Acids Research 13, 2063-2073.

Takagi, J. S., Tokushige, M., Shimura, Y. \& Kanehisa, M. (1986a). L-Aspartate ammonia-lyase and fumarate hydratase share extensive sequence homology. Biochemical and Biophysical Research Communications 132, 568-572.
Takagi, J. S., Tokushige, M. \& Shimura, Y. (1986b). Cloning and nucleotide sequence of the aspartase gene of Pseudomonas fluorescens. Journal of Biochemistry 100, 697-705.

Turner, G. L. \& Gibson, A. H. (1980). Measurement of nitrogen fixation by indirect means. In Methods for Evaluating Biological Nitrogen Fixation, pp. 111-138. Edited by F. J. Bergersen. Chichester: John Wiley.

Woods, S. A. \& GuEst, J. R. (1987). Differential roles of the Escherichia coli fumarases and fnr-dependent expression of fumarase $\mathrm{B}$ and aspartase. FEMS Microbiology Letters 48, 219-224.

Woods, S. A., Miles, J. S., Roberts, R. E. \& Guest, J. R. (1986), Nucleotide sequences of the fumarase $(f u m C)$ and aspartase $(\operatorname{asp} A)$ genes of Escherichia coli K12. Biochemical Journal 237, 547-557.

Woods, S. A., MileS, J. S. \& GuEST, J. R. (1988a). Sequence homologies between argininosuccinase, aspartase and fumarase: a family of structurally-related enzymes. FEMS Microbiology Letters 51, 181-186.

Woods, S. A., Schwartzbach, S. D. \& Guest, J. R. (1988b). Two biochemically distinct classes of fumarase in Escherichia coli. Biochimica et Biophysica Acta 954, 14-26.

Wu, M. \& Tzagoloff, A. (1987). Mitochondrial and cytoplasmic fumarases in Saccharomyces cerevisiae are encoded by a single nuclear gene FUM1. Journal of Biological Chemistry 262, 1227512282.

Yumoto, N. \& Tokushige, M. (1988). Characterization of multiple fumarase proteins in Escherichia coli. Biochemical and Biophysical Research Communications 153, 1236-1243. 